\title{
NDRG2 gene expression pattern in ovarian cancer and its specific roles in inhibiting cancer cell proliferation and suppressing cancer cell apoptosis
}

Fenhong Kang ${ }^{1}$, Yanlong Wang ${ }^{1}$, Yaping Luo ${ }^{1 *}$ and Yongjun Zhang ${ }^{2^{*}}$

\begin{abstract}
Background: The cancer cell metastasis and the acquisition of chemotherapy resistance remain huge challenge for ovarian cancer treatment. Previously, N-myc downstream-regulated gene 2 (NDRG2) serves as a tumor suppressor for many cancers. Here, we attempted to investigate the specific roles of NDRG2 in ovarian cancer.

Methods: The expression levels of NDRG2 were detected by qRT-PCR or Immunoblotting. CCK-8 assay was employed to examine the cell viability of ovarian cancer cells. The colony formation ability was determined by colony formation assay. Flow cytometry analyses were performed to detect the cell apoptosis and cell cycle. Xenograft tumor assay was performed to detect the in vivo function of NDRG2.

Results: We revealed that NDRG2 mRNA expression and protein levels were downregulated within both ovarian cancer tissues and cell lines. The overexpression of NDRG2 dramatically inhibited the cell viability and colony formation and tumor growth, whereas promoted the cell apoptosis, cell cycle arrest in G1 phase within ovarian cancer cells. More importantly, NDRG2 overexpression significantly enhanced the suppressive roles of cisplatin (DDP) in ovarian cancer cell viability. On the contrary, NDRG2 silence exerted opposing effects on ovarian cancer cells.

Conclusions: In summary, we provide a solid experimental basis demonstrating the tumor-suppressive effects of NDRG2 in inhibiting the cell proliferation, enhancing the cell apoptosis, eliciting the cell cycle arrest in G1 phase, and promoting the suppressive effects of DDP on the viability of ovarian cancer cells. NDRG2 administration presents a potent adjuvant treatment for ovarian cancer therapy.
\end{abstract}

Keywords: Ovarian cancer, N-myc downstream-regulated gene 2 (NDRG2), Cell viability, Apoptosis, Cisplatin (DDP)

\footnotetext{
*Correspondence: lyp76700@163.com; legendzhangyongjun@126.com 'Department of Gynecology, Women and Children's Hospital, School of Medicine, Xiamen University, Xiamen 361001, Fujian, China

${ }^{2}$ Department of Pathology, ZhongShan Hospital, Xiamen University, Xiamen 361004, Fujian, China
}

(c) The Author(s). 2020 Open Access This article is licensed under a Creative Commons Attribution 4.0 International License, which permits use, sharing, adaptation, distribution and reproduction in any medium or format, as long as you give appropriate credit to the original author(s) and the source, provide a link to the Creative Commons licence, and indicate if changes were made. The images or other third party material in this article are included in the article's Creative Commons licence, unless indicated otherwise in a credit line to the material. If material is not included in the article's Creative Commons licence and your intended use is not permitted by statutory regulation or exceeds the permitted use, you will need to obtain permission directly from the copyright holder. To view a copy of this licence, visit http://creativecommons.org/licenses/by/4.0/ The Creative Commons Public Domain Dedication waiver (http://creativecommons.org/publicdomain/zero/1.0/) applies to the data made available in this article, unless otherwise stated in a credit line to the data. 


\section{Introduction}

Ovarian cancer is one of the deadliest malignancies in female $[1,2]$. Since the incipient symptoms of ovarian cancer are obscure, most patients received diagnosis until entering the advanced stage [3-5]. Surgical treatment and platinum-based chemotherapy are major therapeutic strategies for ovarian cancers [6]. Unfortunately, these therapeutic methods seem to become less effective with the progression of the cancer. Moreover, the morbidity of the ovarian cancer also remains a higher level due to lack of reliable predictive biomarker, ovarian cancer cells metastasis and the resistance to chemotherapy [7]. Thus, it's necessary to determine ovarian cancer pathophysiology and find new treatment methods.

Interestingly, it has been revealed the correlations between cancer (such as lung, prostate, liver, colorectal and breast cancer) and N-myc downstream-regulated gene 2 (NDRG2) [8-10]. NDRG2 is considered to be a tumor suppressor which contributes to not only hormone, ion, fluid metabolism and other cellular metabolic processes [11, 12], but also stress responses, like those under hypoxic environments and lipid toxicity [13, 14]. It has been demonstrated the correlations between NDRG2 and cancer within neurotumors $[15,16]$, gastroenteric tumors [9, 17], genitourinary tumors [18, 19], breast carcinoma [20, 21], lung carcinoma [10, 22], thyroid carcinoma [23], oral squamous-cell cancer [24], myeloid leukemia [25], and cervical cancer [14]. Collectively, the expression of NDRG2 is reduced within human tumors, while its overexpression suppresses the capacity of cancer cells to proliferate, migrate, metabolize and invade [26]; NDRG2 expression levels are negatively correlated with human cancer clinical and pathological conditions [26]. Nevertheless, little is known about the specific role of NDRG2 within ovarian cancer.

Herein, NDRG2 mRNA and protein expression showed to be monitored within ovarian cancer tissues and cells. Next, NDRG2 overexpression and silence were conducted in three cell lines of ovarian cancer; the specific effects of NDRG2 upon the viability, colony formation ability, apoptosis, cell cycle, and the sensitivity to cisplatin (DDP) treatment of ovarian cancer cells were evaluated. The NDRG2 inhibition capacity towards holding the growth and tumorigenesis of ovarian cancer was determined in vivo. In summary, we attempt to provide a solid experimental basis for understanding the cellular functions of NDRG2 on ovarian cancer cells.

\section{Materials and methods}

\section{Clinical tissue samples}

We collected a total of 6 paired non-cancerous (NC) and ovarian cancer tissues from patients received resection surgeries in Zhongshan hospital with the signed the consent from each patient. All the experiments in the present study were conducted with the approval of the Ethics Committee of Zhongshan hospital. The pathologic type of all samples was confirmed by two independent pathological experts. Tissues were frozen at $80^{\circ} \mathrm{C}$ immediately after sampling until further use.

\section{Cell lines and cell culture}

A normal cell line, human ovarian surface epithelial cell line (HOSE, also known as HOSEpiC), was purchased from ScienCell (Cat. \#7310; Carlsbad, CA, USA) and cultured in Ovarian Epithelial Cell Medium (OEpiCM, Cat. \#7311; ScienCell). Ovarian cancer SKOV3 (ATCC HTB-77 $^{\mathrm{mm}}$ ), OVCAR-3 (ATCC ${ }^{\ominus}$ HTB- $^{-161^{\mathrm{mm}}}$ ), and CAOV3 $\left(\right.$ ATCC $^{\circ}$ HTB- $^{-75^{\mathrm{ma}}}$ ) cell lines were obtained from ATCC (Manassas, VA, USA). SKOV3 cells were cultured in McCoy's 5a Medium Modified (Catalog No. 30-2007; ATCC). CAOV3 cells were cultured in Dulbecco's Modified Eagle's Medium (Catalog No. 30-2002; ATCC). OVCAR-3 cells were cultured in RPMI-1640 Medium (Catalog No. 30-2001; ATCC). All the cells were cultured with $10 \%$ FBS (Invitrogen, Carlsbad, CA, USA) at $37^{\circ} \mathrm{C}$ in $5 \% \mathrm{CO}_{2}$.

Cells were transfected with scramble siRNA (negative control, si-NC; RiboBio, Guangzhou, China) or NDRG2 siRNA (si-NDRG2; RiboBio) with the help of Lipofectamine 3000 reagent (Thermo Fisher Scientific, Waltham, MA, USA). Cells were collected and used for further experiments $48 \mathrm{~h}$ after transfection.

\section{PCR-based analyses}

Total RNA was extracted from target cells with the help of TRIzol reagent (Invitrogen). The reverse transcription of extracted RNAs into cDNA was performed with the help of Maxima First Strand cDNA Synthesis Kits (K1672; Thermo Fisher). The expression of mRNA was determined with an SYBR ${ }^{\bullet}$ Green Real-time PCR Master Mix (Sigma, St. Louis, MO, USA) using GAPDH as an endogenous control. All the results were processed and analyzed using the $2^{-\Delta \Delta \mathrm{Ct}}$ method.

\section{Immunoblotting}

Cell lysate was prepared using RIPA lysis buffer (Applygen, Beijing, China) and proteins were extracted. SDSPAGE (10\%) was used to separate the extracted proteins. After that, proteins were transferred onto PVDF membranes. Nonspecific antigen was blocked by $5 \%$ non-fat milk solution, and the membranes were washed three times using PBST. The membranes were then incubated overnight at $4{ }^{\circ} \mathrm{C}$ with anti-NDRG2 (Cat\# 12015-1-AP, Proteintech, Rosemont, IL, USA), anti-BAX antibody (1:1000, Cat\# ab32503), anti-BCL2 antibody (1:1000, Cat\# ab32124), antiCleaved Caspase-3 antibody (Cat\# ab2302), anti-Caspase-3 antibody (1:500, Cat\# ab13847), anti-cyclin B1 (1:50000, 

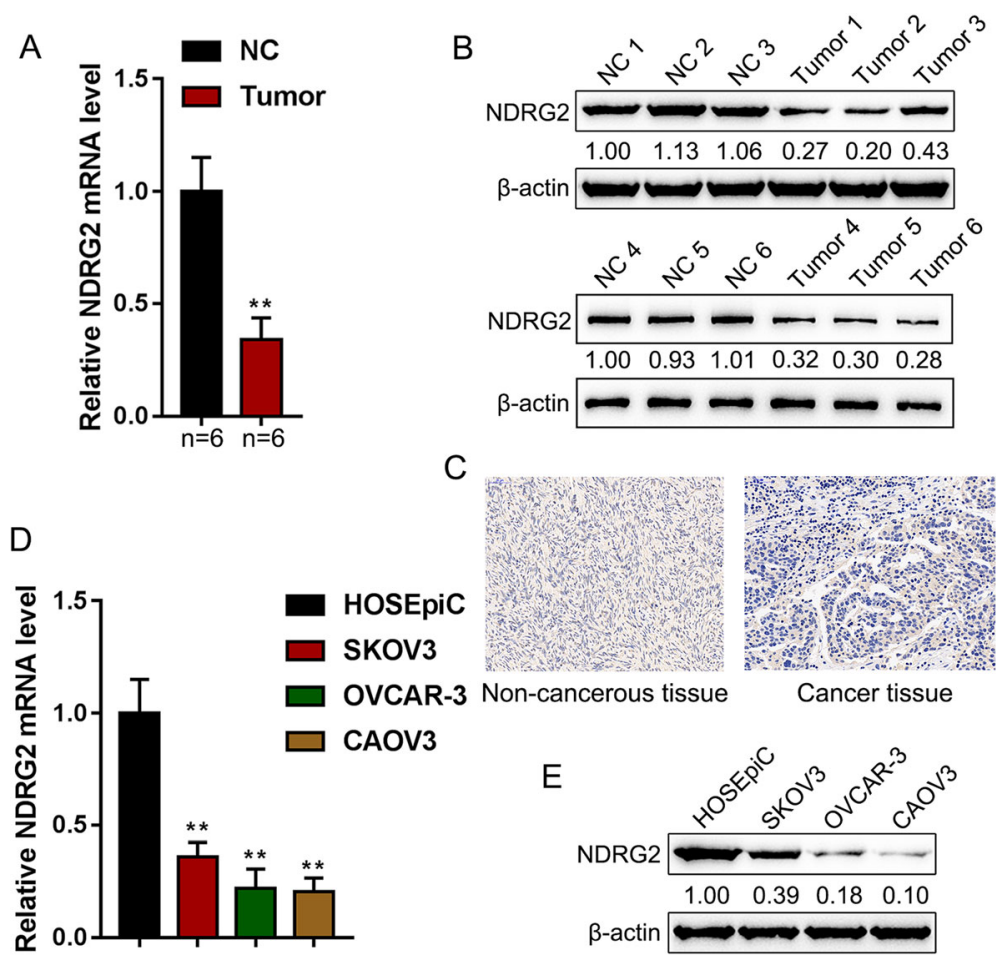

Fig. 1 NDRG2 mRNA expression and protein levels in tissue samples and cell lines (a and $\mathbf{b}$ ) NDRG2 mRNA and protein expression was determined in 6 paired non-cancerous and tumor tissues by real-time PCR and Immunoblotting. c The expressions of NDRG2 protein in noncancerous and tumor tissues was detected by IHC assay. $\mathbf{d}$ and e NDRG2 mRNA and protein expression was determined in one normal cell line and three ovarian cancer cell lines, SKOV3, OVCAR-3, and CAOV3 by real-time PCR and Immunoblotting. ${ }^{* *} P<0.01$

Cat\# ab32053), anti-cyclin A2 (1:2000, Cat\# ab181591) (Abcam, Cambridge, MA, USA) and anti- $\beta$-actin (60008-1Ig, Proteintech). After washing with PBST, the membranes were incubated with appropriate HRP goat anti-mouse/ anti-rabbit IgG (Proteintech) at room temperature. The visualization of all the blots were conducted using enhanced chemiluminescence (ECL; Thermo Fisher).

\section{Cell viability determined by CCK-8 assay}

A CCK-8 kit (Sigma-Aldrich, St. Louis, MO, USA) was employed to examine the cell viability of ovarian cancer cell lines in response to different treatment and/or transfection. Cells were placed into 96 -well plates at a density of $1 \times 10^{4}$ cells/well. CCK- 8 solution was added at $0 \mathrm{~h}$ and $24 \mathrm{~h}$ thereafter and then cells were incubated for $4 \mathrm{~h}$ at $37^{\circ} \mathrm{C}$. The absorbance (OD value) was measured at $450 \mathrm{~nm}$.

\section{Colony formation}

The colony formation ability was determined. Cells were cultured 6-well plates at a density of $1 \times 10^{2}$ cells/well. Fourteen days later, the colonies were fixed with
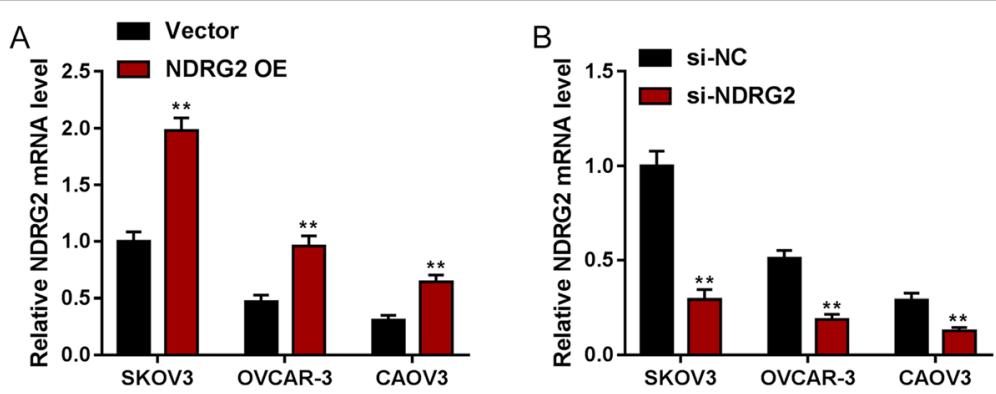

Fig. 2 NDRG2 overexpression or silence in ovarian cancer cells (a) SKOV3, OVCAR-3, and CAOV3 cells were transfected with vector (negative control) or NDRG2 OE, as confirmed by real-time PCR. (b) SKOV3, OVCAR-3, and CAOV3 cells were transfected with si-NC (negative control) or siNDRG2, as confirmed by real-time PCR. ${ }^{* *} P<0.01$ 
methanol and stained with $0.1 \%$ crystal violet (Sigma-Aldrich). After that, the number of visible colonies were counted.

\section{Cell cycle and cell apoptosis determined by flow cytometry}

Flow cytometry analyses were performed to detect the cell apoptosis and cell cycle. For cell apoptosis analysis, cells were collected, resuspended, and added with annexin V-FITC and PI. After 15 min of incubation, the cell apoptosis was analyzed.
For cell cycle analysis, cells were fixed with ethanol (70\%, ice-cold) for $20 \mathrm{~min}$ and added with PI. After 20 min incubation, the cell cycle was analyzed.

\section{Xenograft mice assay in vivo}

Pathogen free conditions were maintained through the lifetime of twelve male BALB/c nude mice (4 weeks old). The approval of xenograft in vivo assay was obtained from Zhongshan hospital. Firstly, overexpression of NDRG2 (Lv-NDRG2 OE) was performed using MISSION ${ }^{\circ}$ shRNA lentiviral particles (Sigma-Aldrich), which were designed to overexpress the production of NDRG2
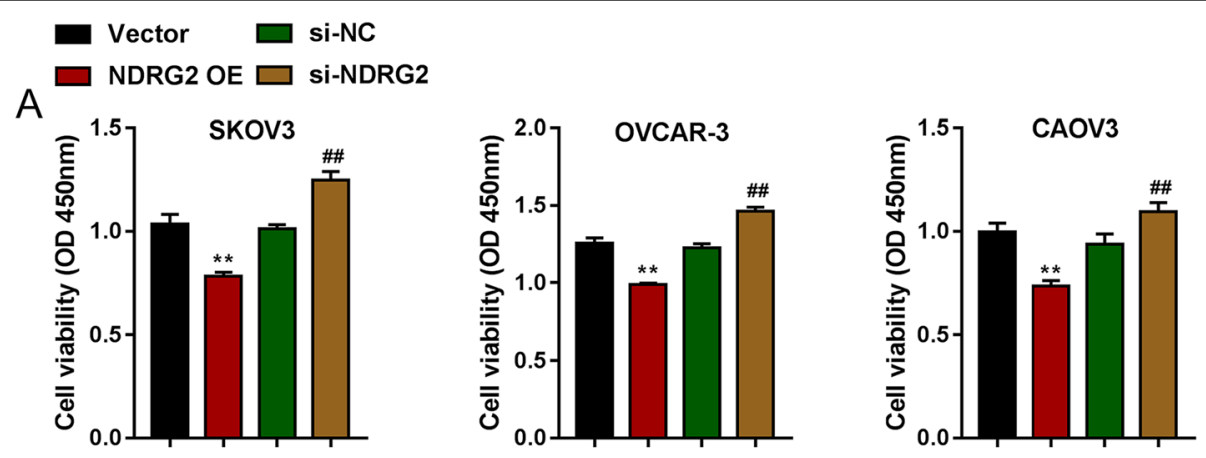

B
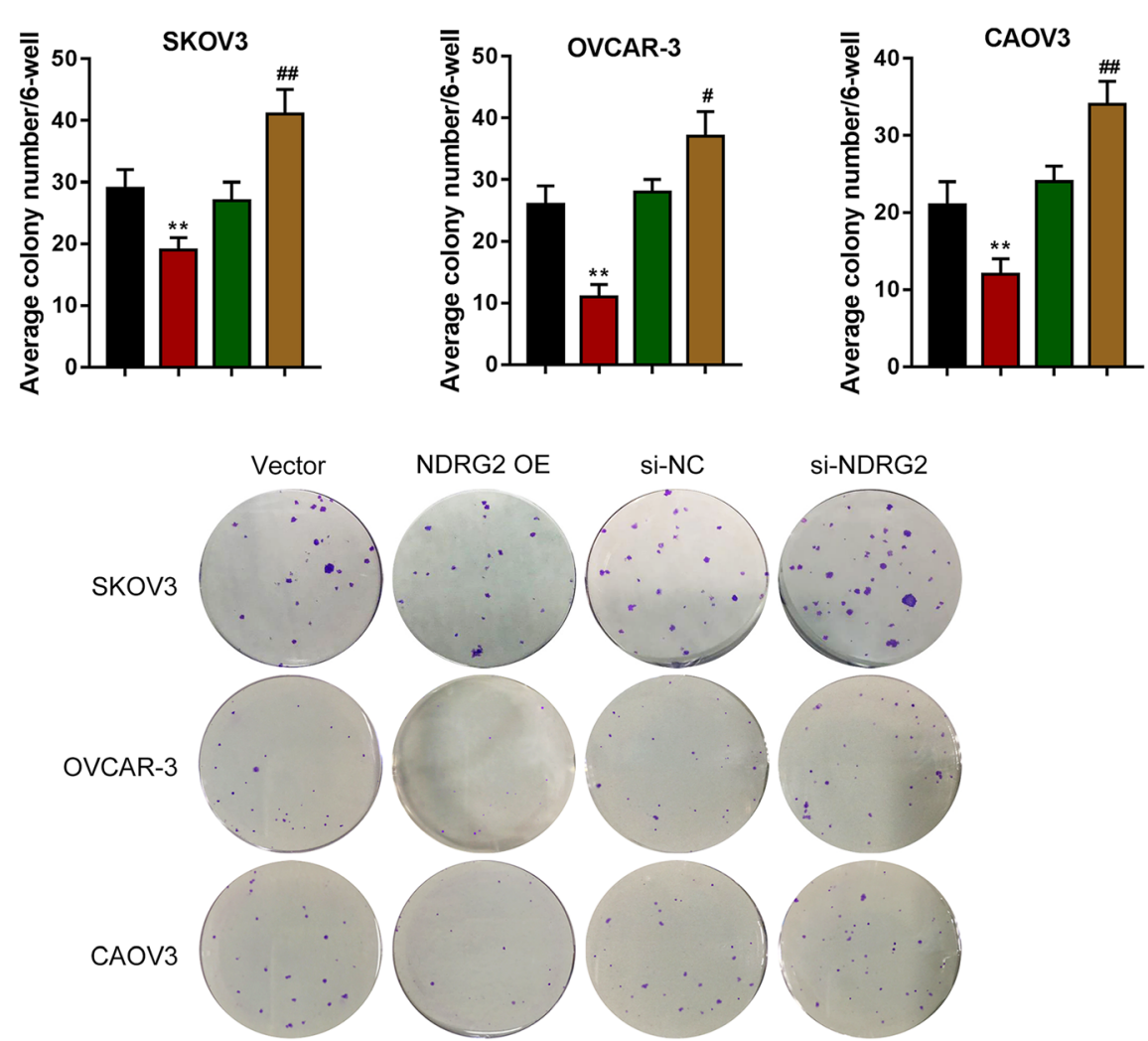

Fig. 3 Effects of NDRG2 on ovarian cancer cell proliferation SKOV3, OVCAR-3, and CAOV3 cells were transfected with vector (negative control), NDRG2 OE, si-NC (negative control), or si-NDRG3 and examined for (a) cell viability by CCK-8; $\mathbf{b}$ colony formation ability. ${ }^{* *} P<0.01$, compared to Vector group; \#\#P<0.01, compared to si-NC group 





(See figure on previous page.)

Fig. 4 Effects of NDRG2 on ovarian cancer cell apoptosis and cell cycle SKOV3, OVCAR-3, and CAOV3 cells were transfected with vector (negative control), NDRG2 OE, si-NC (negative control), or si-NDRG3. a Cell apoptosis was examined by Flow cytometry. The Quadrant 1 (Q1) of the flow diagram represented as dead cells; the Quadrant 2 (Q2) represented as non-viable apoptotic cells; the Quadrant 3 (Q3) represented as viable apoptotic cells; the Quadrant $4(\mathrm{Q} 4)$ represented as viable non-apoptotic cells. The percentage of cell apoptosis is the sum of Q2 and Q3 in the flow diagram. b Western blot assay was adopted to examine apoptosis-related protein BAX, BCL2 and cleaved caspase3/caspase3. and c Cell cycle was detected by Flow cytometry. $\mathbf{d}$ Cell cycle marker protein cyclin B1 and cyclin A2 had been examined by western blot assay. ${ }^{* *} P<0.01$, compared to Vector group; \#\#P<0.01, compared to si-NC group

in SKOV3 cells. The cultures that were transfected with lentiviral particles with negative control vector were used as the control group (Lv-Vector). Subsequently, LvNDRG2 OE or Lv-Vector transfected SKOV3 cells $(1 \times$ $10^{6}$ ) were subcutaneous injected into the armpit of nude mice respectively. Caliper was adapted in measuring tumor volume following the length $\times$ width $^{2} / 2$ formula. The average volume of tumor was measured for 3 times every 3 days. At the termination of the experiment (the 25 th day), mice were killed and the tumor was excised from each mouse to measure the average volume and weight.

\section{Data processing and statistical analysis}

All data collected from three independent experiments were processed and analyzed by GraphPad (San Diego, CA, USA). The data was represented as mean \pm SD. The comparison was conducted using paired or unpaired Student's $t$-test. A $P$ value of less than 0.05 was considered as statistically significant.

\section{Results}

\section{The mRNA and protein expression of NDRG2 within} tissues and cells

To further confirm how NDRG2 affected ovarian cancer, we first verified NDRG2 expression within the tissues and cells of ovarian cancer. The mRNA and protein expression of NDRG2 showed to be dramatically downregulated within ovarian cancer tissues than that in noncancerous tissue samples (Fig. 1a\&b); similarly, the expressions of NDRG2 protein were lower in ovarian cancer tissues than non-cancerous tissue samples by IHC assay (Fig. 1c). Consistently, the mRNA and protein expression of NDRG2 also showed to be remarkably downregulated within three ovarian cancer cells, SKOV3, OVCAR-3, and CAOV3, than that in a normal cell line, HOSE (Fig. 1d\&e).

\section{Involvements of NDRG2 in proliferation, apoptosis, and cell cycle of ovarian cancer cells}

To further investigate the specific effects of NDRG2 on ovarian cancer cells, we conducted NDRG2 overexpression and NDRG2 silence in SKOV3, OVCAR-3, and CAOV3 cells by transfection with vector (negative control), NDRG2 OE, si-NC (negative control), or si-
NDRG3. The transfection efficiency was determined via real-time PCR (Fig. 2a-b).

Next, the effects of NDRG2 overexpression and silence on ovarian cancer cells were evaluated. As revealed by CCK-8 and colony formation analyses, NDRG2 overexpression significantly suppressed, whereas NDRG2 silence promoted the cell viability and colony formation ability of SKOV3, OVCAR-3, and CAOV3 cells (Fig. 3a-b). NDRG2 overexpression significantly enhanced cell apoptosis rate to about $17.02 \%$ (SKOV3 cell), 21.37\% (OVCAR-3 cell) and $17.28 \%$ (CAOV3 cell) respectively, whereas NDRG2 silence suppressed cell apoptosis rate to about $11.67 \%$ (SKOV3 cell), $15.45 \%$ (OVCAR-3 cell) and 10.51\% (CAOV3 cell) respectively (Fig. 4a). Next, western blot assay was adopted to examine apoptosis-related protein BAX, BCL2 and cleaved caspase3/caspase3 in three ovarian cancer cells. NDRG2 overexpression prominently promoted, whereas NDRG2 silence inhibited apoptosisrelated protein expression (Fig. 4b). Moreover, NDRG2 overexpression significantly induced the cell cycle arrested in $\mathrm{G} 1$ phase with increasing the percentage of $\mathrm{G} 1$ phase to about $77.52 \%$ (SKOV3 cell), 78.32\% (OVCAR-3 cell) and $72.21 \%$ (CAOV3 cell), whereas NDRG2 silence exerted an opposing effect with reducing the percentage of G1 phase to about $29.07 \%$ (SKOV3 cell), 45.84\% (OVCAR-3 cell) and $52.24 \%$ (CAOV3 cell) (Fig. 4c). Consistently, the impact of NDRG2 on cell cycle marker protein cyclin B1 and cyclin A2 had been examined by western blot assay. NDRG2 overexpression observably restrained, whereas NDRG2 silence facilitated cell cycle-related protein expression (Fig. 4d). These data indicate that NDRG2 inhibits the cell viability and colony formation, and induces apoptosis and cell cycle arrest in G1 phase, thus acting as a tumor suppressor within ovarian cancer cells.

\section{Effects of NDRG2 on ovarian cancer cell sensitivity to DDP treatment}

To date, DDP is one of the most valid agents of ovarian cancer and other solid tumors [27-29]. After confirming the tumor-suppressive effect of NDRG2 on ovarian cancer cells, we further investigated whether NDRG2 could sensitize ovarian cancer cells to DDP treatment. Firstly, we transfected SKOV3, OVCAR-3, and CAOV3 cells with vector (negative control), NDRG2 OE, si-NC (negative control), or si-NDRG2, after $24 \mathrm{~h}$, SKOV3, OVCAR-3, and 
CAOV3 cells were divided into blank control (untreated) group and DDP group $(2.5 \mu \mathrm{g} / \mathrm{mL}$ DDP for $24 \mathrm{~h})$ and then examined for cell viability. As shown in Fig. 5, DDP treatment dramatically inhibited cell viability; NDRG2 overexpression enhanced the suppressive role of DDP in the viability of ovarian cancer cells, whereas NDRG2 silence

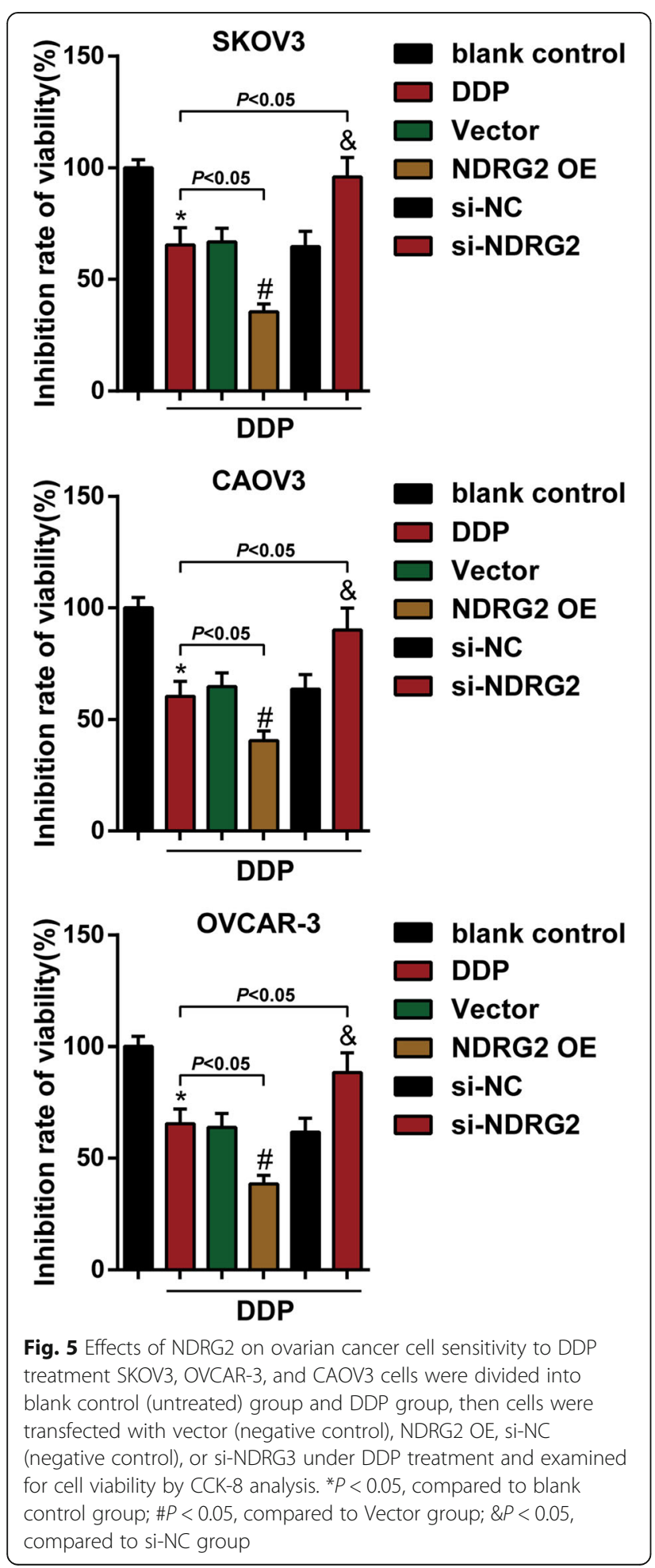

exerted an opposing effect. In summary, NDRG2 could improve the cellular effects of DDP on ovarian cancer cells.

\section{Effects of NDRG2 on the growth of xenograft formed by SKOV3 cells in nude mice}

The NDRG2 inhibition capacity towards holding the growth and tumorigenesis of ovarian cancer in vivo was evaluated on xenograft nude mice model. SKOV3 cells pre-transfected with lentivirus-mediated NDRG2 overexpression or negative control were subcutaneous injected into the armpit of nude mice respectively. The NDRG2 mRNA expression level in Lv-NDRG2 OE group was markedly increased compared to that in Lv-Vector group (Fig. 6a). During the period of xenograft growth in nude mice, measurement of tumor volumes was performed every three days. The results showed the volumes of xenograft formed by SKOV3 cells with NDRG2 overexpression were significantly less than those formed by normal SKOV3 cells since 16th day of implantation (Fig. 6b). At the end of the experiment (the 25th day), mice were euthanized and tumor tissues were excised, the weight (Fig. 6c) and sizes (Fig. 6d) of xenograft formed by SKOV3 cells with NDRG2 overexpression were clearly smaller than those formed by normal SKOV3 cells. Therefore, NDRG2 overexpression attenuated the growth and tumorigenesis of ovarian cancer in vivo.

\section{Discussion}

Herein, we revealed that NDRG2 mRNA expression and protein levels were downregulated within both ovarian cancer tissues and cell lines. The overexpression of NDRG2 dramatically inhibited the cell viability, colony formation and cell cycle marker protein cyclin B1 and cyclin A2 expression levels, whereas promoted the cell apoptosis and apoptosis-related protein BAX, BCL2 and cleaved caspase3/caspase3 expression levels and cell cycle arrest in G1 phase within ovarian cancer cells. More importantly, NDRG2 overexpression significantly enhanced the suppressive roles of DDP in ovarian cancer cell viability. NDRG2 overexpression attenuated the growth and tumorigenesis of ovarian cancer in vivo. On the contrary, NDRG2 silence exerted opposing effects on ovarian cancer cells.

NDRG2 is one member of the NDRG family that contains NDRG1, NDRG2, NDRG3, and NDRG4 [30, 31]. NDRG2 has been reported to be reduced within colorectal cancer, liver cancer, thyroid cancer, glioblastoma, breast cancer and a number of other human cancers $[16$, $17,20,23,32,33]$. Moreover, the increase in NDRG2 expression within cancer cells can be related to improved prognosis in gastric cancer, high-grade glioma and hepatocellular carcinomas [17, 34, 35]. Herein, the mRNA and protein expression of NDRG2 showed to be 

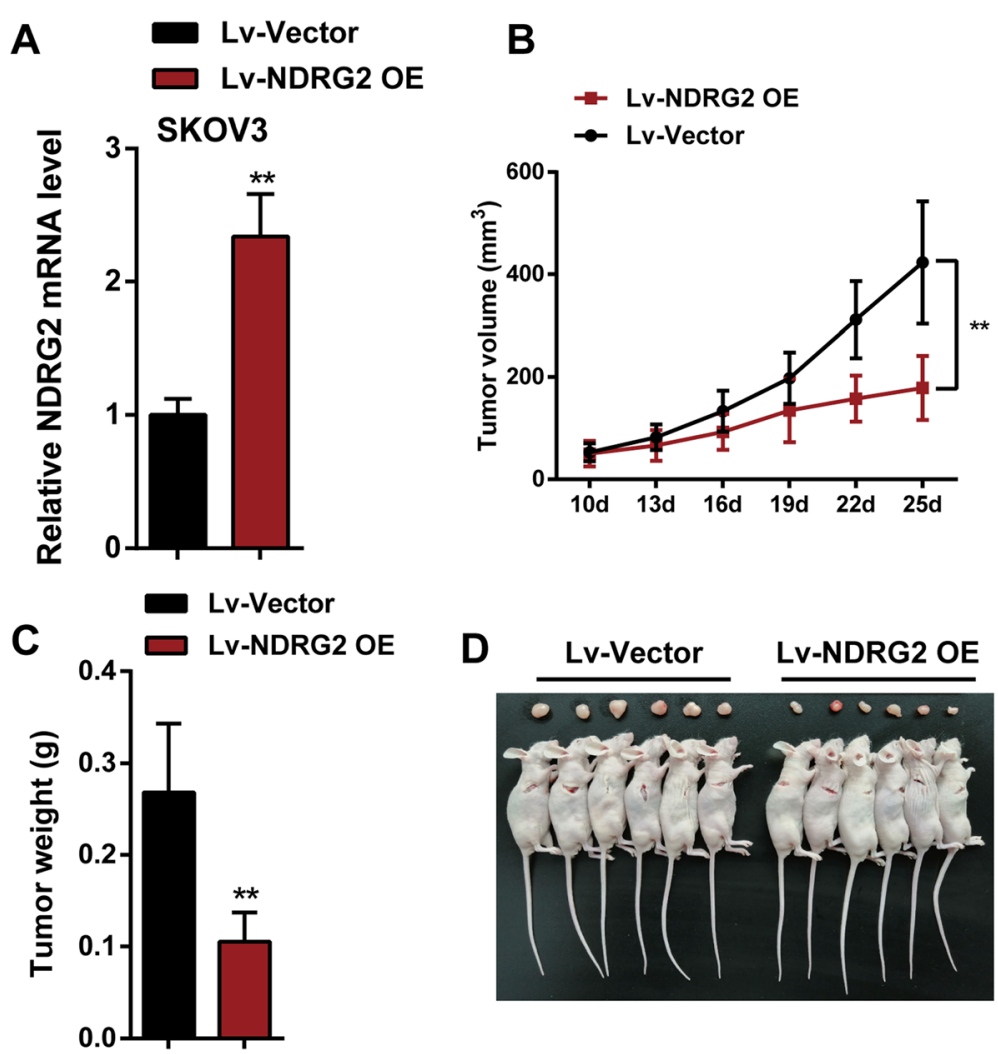

Fig. 6 Effects of NDRG2 on the tumorigenesis of ovarian cancer in nude mice SKOV3 cells pre-transfected with lentivirus-mediated NDRG2 overexpression or negative control were subcutaneous injected into the armpit of nude mice respectively. LV-NDRG2 OE means SKOV3 cells were transfected with lentivirus-mediated NDRG2 overexpression vector. LV-Vector group means SKOV3 cells were transfected with noneffective negative control lentiviral vector. a The NDRG2 mRNA expression level in Lv-NDRG2 OE group was markedly increased compared to that in LvVector group. b Tumor volumes of nude mice were measured every 3 days from the 10th day after injection. Overexpression of NDRG2 significantly slowed down ovarian cancer tumor growth. c Tumors were removed from nude mice 25 days after injection. On the 25 th day, tumor weight of the LV-NDRG2 OE group was significantly lower than that of Lv-Vector group. $\mathbf{d}$ Picture of mice tumors illustrated that overexpression of NDRG2 significantly reduced tumor size. ${ }^{* *} P<0.01$, compared to Lv-Vector group

dramatically downregulated within the ovarian cancer tissues than that in the normal controls. In vitro, the mRNA and protein expression of NDRG2 also showed to be remarkably downregulated within SKOV3, OVCAR-3, and CAOV3 cells than those within a noncancerous ovarian epithelial cell line, HOSE. Since excessive NDRG2 protein within cancer cells leads to significantly decreased cell proliferation $[16,36,37]$ while the increased mRNA expression of NDRG2 can be related to improved prognosis [17, 34], we speculate that NDRG2 might act as a tumor suppressor within ovarian cancer, possibly by regulating ovarian cancer cell proliferation and apoptosis.

To verify the above-mentioned speculation, we conducted NDRG2 overexpression or silence in ovarian cancer cells and evaluated its cellar effects. Consistent with its expression pattern, NDRG2 acts as a tumor suppressor within ovarian cancer cell lines. NDRG2 overexpression dramatically suppressed the proliferation whereas enhanced the apoptosis of ovarian cancer cells, similarly to its effects on other cancers [22, 38-40]. Also, the effects of NDRG2 on the growth of xenograft formed by SKOV3 cells in nude mice had been investigated in the study. NDRG2 overexpression attenuated the growth and tumorigenesis of ovarian cancer in vivo. Besides, the resetting of the G1, S, G2, M phases and other cell cycles can be found in the occurrence and development of tumors. As confirmed by a GO (Gene Ontology) enrichment analysis on the biological process, molecular function and cellular component, the overexpression of NDRG2 can increase the G protein signaling-associated genes while reduce the $M$ phase-associated gene sets, which is consistent with cell cycle analyses [41]. Analyses on the signaling pathways have also revealed the decreased glycosylphosphatidylinositol (GPI)-anchor biosynthesis and protein degradation [41]. It has also been demonstrated by $\mathrm{Ma}$ et al. [19] that G1 arrest can be induced by the expression of NDRG2. NDRG2 was introduced into SW620 cells, after which the cell cycle arrest was observed to arrest at G1/S phase [37]. The 
expression of NDRG2 can effectively inhibit cell cycle resetting within tumors. Herein, we observed similar results that, NDRG2 overexpression dramatically induced the cell cycle arrest in G1 phase and inhibited cell cycle marker protein cyclin B1 and cyclin A2 expression levels in all the three ovarian cancer cell lines, suggesting that NDRG2 might suppress ovarian cancer cell proliferation via affecting the resetting of cancer cell cycle.

Cisplatin is the most common platinum-based chemotherapy drug. Its action mechanism is DNA crosslinking, so its tumor-suppressive activity is broadspectrum and non-cell cycle-specific, leading to the inhibition of DNA replication and transcription and induction of tumor cell apoptosis [42, 43]. Although cisplatin has been considered an effective agent for ovarian cancer treatment, the acquisition and development of drug resistance has emerged as a primary obstacle to its wide clinical application [44]. Previously, Liu et al. [45] reported that NDRG2 silence inhibits the expression of Bcl-2, so that cervical cancer Hela cells can be sensitive to cisplatin. In histiocytic lymphoma U937 cells, NDRG2 could modulate NOX5-ROS-PKR pathway-regulated Bak-to-Mcl-1 ratio to increase the sensitivity to cisplatin [46]. In the present study, NDRG2 overexpression within ovarian cancer cell lines significantly enhanced the suppressive effects of DDP upon the viability of ovarian cancer cells, whereas NDRG2 silence exerted an opposing effect. These data indicate that NDRG2 might sensitize ovarian cancer cells to DDP treatment.

\section{Conclusion}

Taken together, our findings provide a solid experimental basis demonstrating the cellular effects of NDRG2 in inhibiting the cell proliferation, enhancing the cell apoptosis, eliciting the cell cycle arrest in G1 phase, and promoting the suppressive effects of DDP upon the viability of cancer cells. NDRG2 overexpression attenuated the growth and tumorigenesis of ovarian cancer in vivo. Nevertheless, it is still necessary to further study the new strategy of rescuing the abnormally downregulated NDRG2 expression as a promising therapeutic strategy for clinical applications.

\section{Acknowledgments}

Not applicable.

\section{Authors' contributions}

FK carried out the molecular genetic studies, participated in the sequence alignment and drafted the manuscript. YW carried out the immunoassays. YL participated in the design of the study and performed the statistical analysis. YZ conceived of the study and participated in its design and coordination. The author(s) read and approved the final manuscript.

\section{Funding}

This study was supported by Youth scientific research project of Fujian Health and Family Planning Commission (2015-2-51).

\section{Availability of data and materials}

All data generated or analyzed during this study are included in this published article.

\section{Ethics approval and consent to participate}

All procedures performed in studies involving human participants were in accordance with the ethical standards of the Ethics Committee of Zhongshan hospital. All participants signed the informed consent.

\section{Consent for publication}

Not applicable.

\section{Competing interests}

The authors declare that they have no competing interest.

Received: 31 December 2019 Accepted: 14 April 2020

Published online: 28 April 2020

\section{References}

1. Liu C, Zhang Y, Jiang H, Wu H. Association between social support and post-traumatic stress disorder symptoms among Chinese patients with ovarian cancer: a multiple mediation model. PLoS One. 2017;12(5):e0177055.

2. Xia B, Yang S, Liu T, Lou G. miR-211 suppresses epithelial ovarian cancer proliferation and cell-cycle progression by targeting Cyclin D1 and CDK6. Mol Cancer. 2015;14:57.

3. Mueller JJ, Zhou QC, lasonos A, O'Cearbhaill RE, Alvi FA, El Haraki A, Eriksson AG, Gardner GJ, Sonoda Y, Levine DA, et al. Neoadjuvant chemotherapy and primary debulking surgery utilization for advanced-stage ovarian cancer at a comprehensive cancer center. Gynecol Oncol. 2016;140(3):436-42.

4. Li N, Yang L, Wang H, Yi T, Jia X, Chen C, Xu P. MiR-130a and MiR-374a function as novel regulators of Cisplatin resistance in human ovarian Cancer A2780 cells. PLoS One. 2015;10(6):e0128886.

5. Colombo PE, Fabbro M, Theillet C, Bibeau F, Rouanet P, Ray-Coquard I. Sensitivity and resistance to treatment in the primary management of epithelial ovarian cancer. Crit Rev Oncol Hematol. 2014;89(2):207-16.

6. Kim A, Ueda Y, Naka T, Enomoto T. Therapeutic strategies in epithelial ovarian cancer. J Exp Clin Cancer Res. 2012;31:14.

7. Gao Y, Foster R, Yang X, Feng Y, Shen JK, Mankin HJ, Hornicek FJ, Amiji MM, Duan Z. Up-regulation of CD44 in the development of metastasis, recurrence and drug resistance of ovarian cancer. Oncotarget. 2015;6(11): 9313-26.

8. Lozano R, Naghavi M, Foreman K, Lim S, Shibuya K, Aboyans V, Abraham J, Adair T, Aggarwal R, Ahn SY, et al. Global and regional mortality from 235 causes of death for 20 age groups in 1990 and 2010: a systematic analysis for the global burden of disease study 2010. Lancet. 2012;380(9859):2095128.

9. Deuschle U, Schuler J, Schulz A, Schluter T, Kinzel O, Abel U, Kremoser C. FXR controls the tumor suppressor NDRG2 and FXR agonists reduce liver tumor growth and metastasis in an orthotopic mouse xenograft model. PLoS One. 2012;7(10):e43044

10. Wang H, Wang W, Wang X, Cai K, Wu H, Ju Q, Huang Z, Gao X. Reduced NMyc downstream-regulated gene 2 expression is associated with CD24 upregulation and poor prognosis in patients with lung adenocarcinoma. Med Oncol. 2012;29(5):3162-8.

11. Ma J, Liu W, Guo H, Li S, Cao W, Du X, Lei S, Hou W, Xiong L, Yao L, et al. Nmyc downstream-regulated gene 2 expression is associated with glucose transport and correlated with prognosis in breast carcinoma. Breast Cancer Res. 2014;16(2):R27.

12. Li Y, Yang J, Li S, Zhang J, Zheng J, Hou W, Zhao H, Guo Y, Liu X, Dou K et al. N-myc downstream-regulated gene 2, a novel estrogen-targeted gene, is involved in the regulation of Na+/K+-ATPase. J Biol Chem. 2011; 286(37):32289-99

13. Shen L, Liu X, Hou W, Yang G, Wu Y, Zhang R, Li X, Che H, Lu Z, Zhang Y, et al. NDRG2 is highly expressed in pancreatic beta cells and involved in protection against lipotoxicity. Cell Mol Life Sci. 2010;67(8):1371-81.

14. Liu J, Zhang J, Wang X, Li Y, Chen Y, Li K, Zhang J, Yao L, Guo G. HIF-1 and NDRG2 contribute to hypoxia-induced radioresistance of cervical cancer Hela cells. Exp Cell Res. 2010;316(12):1985-93.

15. Li L, Wang J, Shen X, Wang L, Li X, Liu Y, Shi M, Zhao G, Deng Y. Expression and prognostic value of NDRG2 in human astrocytomas. J Neurol Sci. 2011; 308(1-2):77-82. 
16. Deng Y, Yao L, Chau L, Ng SS, Peng Y, Liu X, Au WS, Wang J, Li F, Ji S, et al. $\mathrm{N}$-Myc downstream-regulated gene 2 (NDRG2) inhibits glioblastoma cell proliferation. Int J Cancer. 2003;106(3):342-7.

17. Lee DC, Kang YK, Kim WH, Jang YJ, Kim DJ, Park IY, Sohn BH, Sohn HA, Lee HG, Lim JS, et al. Functional and clinical evidence for NDRG2 as a candidate suppressor of liver cancer metastasis. Cancer Res. 2008:68(11):4210-20.

18. Ren GF, Tang L, Yang AQ, Jiang WW, Huang YM. Prognostic impact of NDRG2 and NDRG3 in prostate cancer patients undergoing radical prostatectomy. Histol Histopathol. 2014;29(4):535-42.

19. Ma JJ, Liao CG, Jiang X, Zhao HD, Yao LB, Bao TY. NDRG2 suppresses the proliferation of clear cell renal cell carcinoma cell A-498. J Exp Clin Cancer Res. 2010;29:103.

20. Lorentzen A, Lewinsky RH, Bornholdt J, Vogel LK, Mitchelmore C. Expression profile of the N-myc downstream regulated gene 2 (NDRG2) in human cancers with focus on breast cancer. BMC Cancer. 2011;11:14.

21. Jeschke J, Van Neste L, Glockner SC, Dhir M, Calmon MF, Deregowski V, Van Criekinge W, Vlassenbroeck I, Koch A, Chan TA, et al. Biomarkers for detection and prognosis of breast cancer identified by a functional hypermethylome screen. Epigenetics. 2012;7(7):701-9.

22. Li R, Yu C, Jiang F, Gao L, Li J, Wang Y, Beckwith N, Yao L, Zhang J, Wu G. Overexpression of N-Myc downstream-regulated gene 2 (NDRG2) regulates the proliferation and invasion of bladder cancer cells in vitro and in vivo. PLoS One. 2013;8(10):e76689.

23. Zhao H, Zhang J, Lu J, He X, Chen C, Li X, Gong L, Bao G, Fu Q, Chen S, et al. Reduced expression of N-Myc downstream-regulated gene 2 in human thyroid cancer. BMC Cancer. 2008;8:303.

24. Furuta $\mathrm{H}$, Kondo Y, Nakahata S, Hamasaki M, Sakoda S, Morishita K. NDRG2 is a candidate tumor-suppressor for oral squamous-cell carcinoma. Biochem Biophys Res Commun. 2010;391(4):1785-91.

25. Tschan MP, Shan D, Laedrach J, Eyholzer M, Leibundgut EO, Baerlocher GM, Tobler A, Stroka D, Fey MF. NDRG1/2 expression is inhibited in primary acute myeloid leukemia. Leuk Res. 2010;34(3):393-8.

26. Hu W, Fan C, Jiang P, Ma Z, Yan X, Di S, Jiang S, Li T, Cheng Y, Yang Y. Emerging role of $\mathrm{N}$-myc downstream-regulated gene 2 (NDRG2) in cancer. Oncotarget. 2016;7(1):209-23.

27. Hou L, Hou X, Wang L, Li Z, Xin B, Chen J, Gao X, Mu H. PD98059 impairs the cisplatin-resistance of ovarian cancer cells by suppressing ERK pathway and epithelial mesenchymal transition process. Cancer Biomark. 2017;21(1): 187-94.

28. Kelland LR. Emerging drugs for ovarian cancer. Expert Opin Emerg Drugs. 2005;10(2):413-24.

29. Mei L, Chen H, Wei DM, Fang F, Liu GJ, Xie HY, Wang X, Zou J, Han X, Feng D. Maintenance chemotherapy for ovarian cancer. Cochrane Database Syst Rev. 2010:9:CD007414.

30. Melotte V, Qu X, Ongenaert M, van Criekinge W, de Bruine AP, Baldwin HS, van Engeland $\mathrm{M}$. The $\mathrm{N}$-myc downstream regulated gene (NDRG) family: diverse functions, multiple applications. FASEB J. 2010;24(11):4153-66.

31. Qu X, Zhai Y, Wei H, Zhang C, Xing G, Yu Y, He F. Characterization and expression of three novel differentiation-related genes belong to the human NDRG gene family. Mol Cell Biochem. 2002;229(1-2):35-44.

32. Lorentzen A, Vogel LK, Lewinsky RH, Saebo M, Skjelbred CF, Godiksen S, Hoff G, Tveit KM, Lothe IM, Ikdahl T, et al. Expression of NDRG2 is downregulated in high-risk adenomas and colorectal carcinoma. BMC Cancer. 2007;7:192.

33. Tepel M, Roerig P, Wolter M, Gutmann DH, Perry A, Reifenberger G, Riemenschneider MJ. Frequent promoter hypermethylation and transcriptional downregulation of the NDRG2 gene at $14 \mathrm{q} 11.2$ in primary glioblastoma. Int J Cancer. 2008;123(9):2080-6.

34. Phillips HS, Kharbanda S, Chen R, Forrest WF, Soriano RH, WU TD, Misra A, Nigro JM, Colman H, Soroceanu L, et al. Molecular subclasses of high-grade glioma predict prognosis, delineate a pattern of disease progression, and resemble stages in neurogenesis. Cancer Cell. 2006;9(3):157-73.

35. Choi SC, Yoon SR, Park YP, Song EY, Kim JW, Kim WH, Yang Y, Lim JS, Lee $\mathrm{HG}$. Expression of NDRG2 is related to tumor progression and survival of gastric cancer patients through Fas-mediated cell death. Exp Mol Med. 2007:39(6):705-14.

36. Park Y, Shon SK, Kim A, Kim KI, Yang Y, Cho DH, Lee MS, Lim JS. SOCS1 induced by NDRG2 expression negatively regulates STAT3 activation in breast cancer cells. Biochem Biophys Res Commun. 2007;363(2):361-7.
37. Kim YJ, Yoon SY, Kim JT, Choi SC, Lim JS, Kim JH, Song EY, Lee HG, Choi I, Kim JW. NDRG2 suppresses cell proliferation through down-regulation of AP-1 activity in human colon carcinoma cells. Int J Cancer. 2009;124(1):7-15.

38. Ma J, Liu W, Yan X, Wang Q, Zhao Q, Xue Y, Ren H, Wu L, Cheng Y, Li S, et al. Inhibition of endothelial cell proliferation and tumor angiogenesis by up-regulating NDRG2 expression in breast cancer cells. PLoS One. 2012;7(2): e32368.

39. Li Z, Sun $\mathrm{Y}$, Wan $\mathrm{H}$, Chai F. Overexpression of $\mathrm{N}$-myc downstream regulated gene 2 (NDRG2) inhibits proliferation, migration and promotes apoptosis in SW480 rectal cancer cells. Xi Bao Yu Fen Zi Mian Yi Xue Za Zhi. 2017;33(1): 48-52.

40. Yang $C L$, Zheng XL, Ye K, Ge H, Sun YN, Lu YF, Fan QX. NDRG2 suppresses proliferation, migration, invasion and epithelial-mesenchymal transition of esophageal cancer cells through regulating the AKT/XIAP signaling pathway. Int J Biochem Cell Biol. 2018;99:43-51.

41. Liu X, Niu T, Liu X, Hou W, Zhang J, Yao L. Microarray profiling of HepG2 cells ectopically expressing NDRG2. Gene. 2012;503(1):48-55.

42. Xie Q, Wang S, Zhao Y, Zhang Z, Qin C, Yang X. MiR-519d impedes cisplatin-resistance in breast cancer stem cells by down-regulating the expression of MCL-1. Oncotarget. 2017;8(13):22003-13.

43. Xu YY, Wu TT, Zhou SH, Bao YY, Wang QY, Fan J, Huang YP. Apigenin suppresses GLUT-1 and p-AKT expression to enhance the chemosensitivity to cisplatin of laryngeal carcinoma Hep-2 cells: an in vitro study. Int J Clin Exp Pathol. 2014;7(7):3938-47.

44. Yu PN, Yan MD, Lai HC, Huang RL, Chou YC, Lin WC, Yeh LT, Lin YW. Downregulation of miR-29 contributes to cisplatin resistance of ovarian cancer cells. Int J Cancer. 2014;134(3):542-51.

45. Liu J, Yang L, Zhang J, Zhang J, Chen Y, Li K, Li Y, Li Y, Yao L, Guo G. Knockdown of NDRG2 sensitizes cervical cancer Hela cells to cisplatin through suppressing Bcl-2 expression. BMC Cancer. 2012;12:370.

46. Park S, Oh SS, Lee KW, Lee YK, Kim NY, Kim JH, Yoo J, Kim KD. NDRG2 contributes to cisplatin sensitivity through modulation of BAK-to-mcl-1 ratio. Cell Death Dis. 2018;9(2):30.

\section{Publisher's Note}

Springer Nature remains neutral with regard to jurisdictional claims in published maps and institutional affiliations.
Ready to submit your research? Choose BMC and benefit from:
- fast, convenient online submission
- thorough peer review by experienced researchers in your field
- rapid publication on acceptance
- support for research data, including large and complex data types
- gold Open Access which fosters wider collaboration and increased citations
- maximum visibility for your research: over $100 \mathrm{M}$ website views per year
At $\mathrm{BMC}$, research is always in progress. 